\title{
Polysaccharide isolated from the liquid culture broth of Inonotus obliquus suppresses invasion of B16-F10 melanoma cells via AKT/NF-кB signaling pathway
}

\author{
KI RIM LEE ${ }^{1 *}$, JONG SEOK LEE $^{2 *}$, SARAH LEE $^{2}$, YOUN KYOUNG SON ${ }^{2}$, \\ GA RYUN KIM ${ }^{2}$, YE CHAN SIM ${ }^{1}$, JEONG EUN SONG ${ }^{1}$, SUK-JIN HA ${ }^{1}$ and EOCK KEE HONG ${ }^{1}$ \\ ${ }^{1}$ Department of Bioengineering and Technology, College of Engineering, Kangwon National University, \\ Chuncheon, Gangwon-do 24341; ${ }^{2}$ Biological and Genetic Resources Assessment Division, \\ National Institute of Biological Resources, Incheon 22689, Republic of Korea
}

Received July 23, 2015; Accepted July 4, 2016

DOI: $10.3892 / \mathrm{mmr} .2016 .5771$

\begin{abstract}
A number of polysaccharides exhibit pharmacological activities. Polysaccharides derived from Inonotus obliquus (PLIO) appear to have various potential pharmacological properties, including anti-tumor activity. However, the molecular mechanisms underlying these properties remain to be elucidated. The present study investigated the anti-metastatic potential of PLIO and the underlying signaling pathways in B16-F10 murine melanoma cells using the MTT colorimetric assay, in vitro migration and invasion assays, and flow cytometric and western blot analyses. PLIO inhibited the invasion of B16-F10 cells and suppressed the expression of matrix metalloproteinases. PLIO treatment inhibited nuclear factor $-\kappa \mathrm{B}(\mathrm{NF}-\kappa \mathrm{B})$ nuclear translocation in B16-F10 cells. In addition, PLIO treatment inhibited the phosphorylation of c-Jun N-terminal kinases and AKT. These results suggest that PLIO may suppress the invasion of highly metastatic melanoma cells via inhibition of the $\mathrm{AKT} / \mathrm{NF}-\kappa \mathrm{B}$ signaling pathways.
\end{abstract}

\section{Introduction}

Inonotus obliquus has been commonly used in Asian and Russian folk medicine for thousands of years due its health-promoting properties and relatively low toxicity, it has been widely studied in recent years. It has been demonstrated

Correspondence to: Dr Eock Kee Hong, Department of Bioengineering and Technology, College of Engineering, Kangwon National University, 192-1, Hyoja-2-dong, Chuncheon, Gangwon-do 24341, Republic of Korea

E-mail: ekhong@kangwon.ac.kr

${ }^{*}$ Contributed equally

Key words: Inonotus obliquus, B16-F10 melanoma cells, invasion, matrix metalloproteinase, $\mathrm{NF}-\kappa \mathrm{B}$ that I. obliquus, a fungus in the Hymenochaetaceae family, contain numerous steroids, phenolic compounds and polysaccharides that have various biological activities (1). Numerous mushrooms have biologically active polysaccharides in their fruiting bodies, cultured mycelium, and culture broth. I. obliquus has been reported to exhibit various beneficial biological properties, including anti-tumor, anti-metastatic, anti-oxidative, anti-viral, anti-diabetes, and immunomodulatory activities (2-6). The fruiting bodies of wild I. obliquus are expensive due to host specificity and rarity in nature. Thus, the production of adequate amounts of the fruiting bodies of wild I. obliquus for use as a different chemotherapeutic option is currently impractical. Liquid cultures of mushrooms, in addition to the culture broth and mycelia, are a promising alternative to wild resources for the efficient production of polysaccharides, as this method has high productivity and low cost. It is required to demonstrate that fermented polysaccharides exhibit medicinal and nutritional values that are comparable to those from medicinal mushroom fruiting bodies (7), as previous studies have reported that the mycelial biomass of medicinal mushrooms possesses different pharmacologic properties from those of the mushroom fruiting bodies $(8,9)$. Thus, the present study aimed to investigate the biological activities of polysaccharides from liquid culture with mushroom mycelia.

Cancer is an important cause of human mortality worldwide, and numerous cancer treatments, including cancer chemotherapeutic agents, are known to result in adverse side effects $(10,11)$. Metastasis is a characteristic of highly malignant tumor cells leading to poor clinical outcomes. The excessive degradation of extracellular matrix (ECM) is a characteristic of tumor metastasis and invasion (12). Furthermore, matrix metalloproteinases (MMPs) in humans have been identified as key factors involved in these processes. MMPs are a family of zinc-dependent endopeptidases that facilitate proteolytic cleavage of ECM components, including proteoglycan, collagen, laminin, elastin, and fibronectin (13). It has been demonstrated that the phosphatidylinositol 3-kinase (PI3K)/AKT and mitogen-activated protein kinase (MAPK) signaling pathways regulate metastasis in various types of 
cancer cell (14). Activation of the PI3K-AKT pathway may increase the expression levels of MMP directly, phosphorylate $\mathrm{I} \kappa \mathrm{B}$ kinases and activate nuclear factor- $\kappa \mathrm{B}(\mathrm{NF}-\kappa \mathrm{B})$ signaling pathways, which promote $\mathrm{NF}-\kappa \mathrm{B}$ translocation to the nucleus and then regulates $\mathrm{NF}-\kappa \mathrm{B}$-dependent MMP transcription (15). $\mathrm{NF}-\kappa \mathrm{B}$ is a key transcription factor in cancer cells, which has been associated with cancer development and maintenance, including preventing apoptosis, growth factor-independent proliferation, and tissue invasion and metastasis (16).

Our previous studies have demonstrated that polysaccharides from the I. obliquus fruit body exhibit anti-metastatic activities in B16-F10 murine melanoma cells and A549 human non-small cell lung carcinoma cells $(17,18)$. However, the activities of polysaccharides isolated from liquid cultures of I. obliquus (PLIO) remain to be elucidated. Thus, the present study aimed to investigate the anti-metastatic effects and the potential underlying signaling pathways involved in PLIO treatment of the highly metastatic B16-F10 murine melanoma cells in vitro.

\section{Materials and methods}

Materials. Streptomycin, fetal bovine serum (FBS), and penicillin $\mathrm{G}$ and were purchased from Gibco (Thermo Fisher Scientific, Inc., Waltham, MA, USA). Dulbecco's modified Eagle's medium (DMEM) was obtained from Lonza Group, Ltd. (Basel, Switzerland). Isopropyl alcohol and 3-(4,5-dimethylthiazol-2-yl)-2,5-diphenyltetrazolium bromide (MTT) were obtained from Sigma-Aldrich. (St.Louis, MO,USA). Antibodies against extracellular signal-regulated kinase (ERK; 1:1,000 dilution; rabbit monoclonal antibody; cat. no. 4695), phosphorylated (p)-ERK (1:1,000 dilution; Thr202/Tyr204 rabbit polyclonal antibody; cat. no. 9101S), stress-activated protein kinase/c-Jun N-terminal kinase (SAPK/JNK; 1:1,000 dilution; rabbit polyclonal antibody; cat. no. 9252), p-SAPK/JNK (1:1,000 dilution; Thr183/Tyr185 mouse monoclonal antibody; cat. no. 9255S), p38 MAPK (1:1,000 dilution; rabbit polyclonal antibody; cat. no. 9212), p-p38MAPK (1:1,000 dilution; Thr180/Tyr182 rabbit monoclonal antibody; cat. no. 4631S) and NF- $\mathrm{NB}$ p65 (1:1,000 dilution; rabbit polyclonal antibody; cat. no. 3034), and horseradish peroxidase (HRP)-conjugated anti-rabbit IgG (1:2,000 dilution; cat. no. 7074) were purchased from Cell Signaling Technology, Inc. (Danvers, MA, USA). MMP-2 (1:1,000 dilution; rabbit polyclonal antibody; cat. no. 4022), MMP-7 (1:1,000 dilution; rabbit monoclonal antibody; cat. no. 3801), MMP-9 (1:1,000 dilution; rabbit polyclonal antibody; cat. no. 3852), $\beta$-actin (1:1,000 dilution; mouse monoclonal antibody; cat. no. sc-47778), and HRP-conjugated goat anti-mouse $\operatorname{IgG}$ (1:2,000 dilution; cat. no. sc-2005) were obtained from Santa Cruz Biotechnology, Inc. (Dallas, TX, USA) or BD Biosciences (Franklin Lakes, NJ, USA). All other chemicals were of analytical grade.

Preparation of polysaccharides from the broth of I. obliquus culture. Exopolysaccharide from I. obliquus liquid culture broth was isolated using previously described methods (19). Briefly, I. obliquus KCTC 26147 was inoculated at 5\% (v/v) and cultivated for 7 days at $25^{\circ} \mathrm{C}, 600 \mathrm{xg}$, with an uncontrolled $\mathrm{pH}$ in a modified medium containing $40 \mathrm{~g} / 1$ glucose, $5 \mathrm{~g} / 1$ yeast extract, $1 \mathrm{~g} / 1 \mathrm{MgSO}_{4} \cdot 7 \mathrm{H}_{2} \mathrm{O}$, and $2 \mathrm{~g} / 1 \mathrm{KH}_{2} \mathrm{PO}_{4}$. After 7 days of cultivation, the culture broth was centrifuged at $12,000 \mathrm{x} \mathrm{g}$ for 20 min at $4^{\circ} \mathrm{C}$. Polysaccharides were precipitated from the liquid culture broth using $75 \%$ ethanol and centrifuged at 8,000 rpm for $20 \mathrm{~min}$. The precipitated polysaccharides were resuspended, dialyzed against distilled water for 3 days to remove low-molecular-weight compounds, and then freeze-dried.

Cell culture. The B16-F10 murine melanoma cell line was obtained from the Korean Cell Line Bank (Seoul, South Korea). Cells were grown in complete DMEM medium supplemented with $10 \%$ heat-inactivated FBS, $100 \mu \mathrm{g} / \mathrm{ml}$ streptomycin, and $100 \mathrm{U} / \mathrm{ml}$ penicillin. Cells were maintained at $37^{\circ} \mathrm{C}$ in a humidified $5 \% \mathrm{CO}_{2}$ incubator.

Cell viability. Cell viability was assessed using the MTT colorimetric assay, as previously described (20). Cells were pre-incubated in 12 -well plates for $24 \mathrm{~h}$ at $37^{\circ} \mathrm{C}$ in a humidified $5 \%$ $\mathrm{CO}_{2}$ incubator. PLIO at different concentrations $(1-1,000 \mu \mathrm{g} / \mathrm{ml})$ was incubated with the cells for $24 \mathrm{~h}$. Following incubation, cells were washed with $1 \mathrm{X}$ phosphate-buffered saline (PBS) in order to remove dead cells and $0.5 \mathrm{mg} / \mathrm{ml}$ of MTT solution was then added to each well. After $2 \mathrm{~h}$ incubation, formazan crystals in each well were dissolved in isopropyl alcohol to solubilize the formazan salt formed. The absorbance was determined at a wavelength of $595 \mathrm{~nm}$ using a microplate reader.

Flow cytometry. A fluorescein isothiocyanate (FITC)-labeled Annexin V/propidium iodide (PI) apoptosis detection kit (Molecular Probes; Thermo Fisher Scientific, Inc.) was used to determine the level of apoptosis in tumor cells, according to the manufacturer's protocols. Briefly, cells were harvested using trypsin/EDTA solution, washed with PBS, and centrifuged at $600 \mathrm{x}$ g for $5 \mathrm{~min}$ at room temperature to pellet the cells. Cell concentration was adjusted to $1 \times 10^{6}$ cells $/ \mathrm{ml}$ and the cells were resuspended in binding buffer (10 mM HEPES, $140 \mathrm{mM} \mathrm{NaCl}$, and $2.5 \mathrm{mM} \mathrm{CaCl}_{2}$, at $\mathrm{pH}$ 7.4) prior to staining with FITC-labeled Annexin V and PI for $15 \mathrm{~min}$ at room temperature in light-protected conditions. Flow cytometric analysis was performed using a FACSCalibur flow cytometer (BD Biosciences) within $1 \mathrm{~h}$ after staining. The percentage of apoptotic cells was calculated using the CellQuest software program (version 4.0.4; BD Biosciences). The apoptotic cell rate was calculated as the sum of cells in the early and late phase of apoptosis divided by the total number of events recorded by the flow cytometer.

In vitro migration and invasion assay. Six-well chambers with polycarbonate filters with a pore size of $8.0 \mu \mathrm{m}$ were used to perform the migration assays. The filters (Corning Incorporated, Corning, NY, USA) were coated with gelatin (Sigma-Aldrich). The cells were seeded to the upper part of the chamber at a density of $1 \times 10^{6}$ cells $/ \mathrm{ml}$ with or without PLIO (50 or $100 \mu \mathrm{g} / \mathrm{ml}$ ). In the lower chamber, DMEM containing $10 \%$ FBS served as a source of chemoattractants. Following incubtion for $24 \mathrm{~h}$, cells that had migrated through the gelatin were stained with $2 \%$ crystal violet. The non-migrated cells in the upper chamber were removed with a cotton swab. Images of the migrated cells were captured and the cells were counted under a light microscope (magnification, $x 40$ ). Cell invasion assays were performed using a Matrigel-coated 
Transwell chamber. The cells $\left(1 \times 10^{6}\right.$ cells $\left./ \mathrm{ml}\right)$ were seeded to the upper chamber of the Transwell insert with or without PLIO (50 or $100 \mu \mathrm{g} / \mathrm{ml}$ ) in serum-free medium. In the lower chamber, DMEM medium containing 10\% FBS was used as a source of chemoattractants. Following incubation, cells that had invaded through the Matrigel were fixed with $4 \%$ formaldehyde in PBS, stained with $2 \%$ crystal violet, images were captured and cells were counted under a light microscope (magnification, x40) (21).

Western blot analysis. Following PLIO treatment (25, 50 or $100 \mu \mathrm{g} / \mathrm{ml})$, the cells were rinsed with PBS twice and were lysed in lysis buffer [10 mM NaH${ }_{2} \mathrm{PO}_{4} / \mathrm{NaHPO}_{4}(\mathrm{pH} 7.5)$, $10 \mathrm{mM}$ Tris-HCl (pH 7.5), $1 \%$ Triton X-100, $130 \mathrm{mM} \mathrm{NaCl}$, $10 \mathrm{mM} \mathrm{NaPPi}, 2 \mu \mathrm{g} / \mathrm{ml}$ pepstatin A, and $1 \mathrm{mM}$ phenylmethylsulfonyl fluoride] on ice for $30 \mathrm{~min}$. The cell lysates were centrifuged of $12,000 \times \mathrm{g}$ for $20 \mathrm{~min}$ at $4^{\circ} \mathrm{C}$ to remove cell debris and the supernatant was collected. Nuclear extracts were prepared using a nuclear extraction kit (Panomics Inc., Fremont, CA, USA) according to the manufacturer's protocol. Protein content was determined using a Bio-Rad Protein assay kit (Bio-Rad Laboratories, Inc., Hercules, CA, USA). Equal quantities of nuclear and cytosolic protein samples (50 $\mu \mathrm{g}$ per lane) were loaded on 10-15\% SDS-PAGE for separation, and transferred onto $0.2 \mathrm{~mm}$ Immun-Blot nitrocellulose membranes (Bio-Rad Laboratories, Inc.) by electroblotting. The blot was blocked with $1.5 \%$ non-fat milk in $1 \mathrm{X}$ Tris-buffered saline containing $0.1 \%$ Tween-20 (TBST) for $1 \mathrm{~h}$, followed by incubation with the specific primary antibodies at $4^{\circ} \mathrm{C}$ overnight. The blot was finally incubated with HRP-conjugated secondary antibodies. The membranes were washed with TBS-T after each antibody binding reaction. Detection of protein-antibody complexes was conducted using an enhanced chemiluminescence kit (EMD Millipore, Billerica, MA, USA) followed by exposure to X-ray film.

Statistical analysis. All measurements were from at least three independent experiments and all results are presented as the mean \pm standard error of the mean. The data were analyzed using Student's t-test or nonparametric analysis of variance Duncan's multiple range tests were performed to compare multiple groups when appropriate. $\mathrm{P}<0.05$ was considered to indicate a statistically significant difference.

\section{Results}

Treatment with PLIO at low concentrations had no effect on cell viability in melanoma cells. The effect of PLIO on the viability of murine melanoma cell B16-F10 was determined using the MTT assay. Various concentrations $(0-1,000 \mu \mathrm{g} / \mathrm{ml})$ of PLIO were added to the cells followed by incubation for $24 \mathrm{~h}$. Cell viability was determined to be $89 \%$ at $200 \mu \mathrm{g} / \mathrm{ml}$ PLIO compared with the control (Fig. 1). These results indicated that PLIO at lower concentrations (0 to $200 \mu \mathrm{g} / \mathrm{ml}) \mathrm{did}$ not affect cell viability.

Low concentrations of PLIO did not induce apoptosis of melanoma cells. To determine whether PLIO induces cellular apoptosis in melanoma cells, FITC-labeled Annexin V and PI

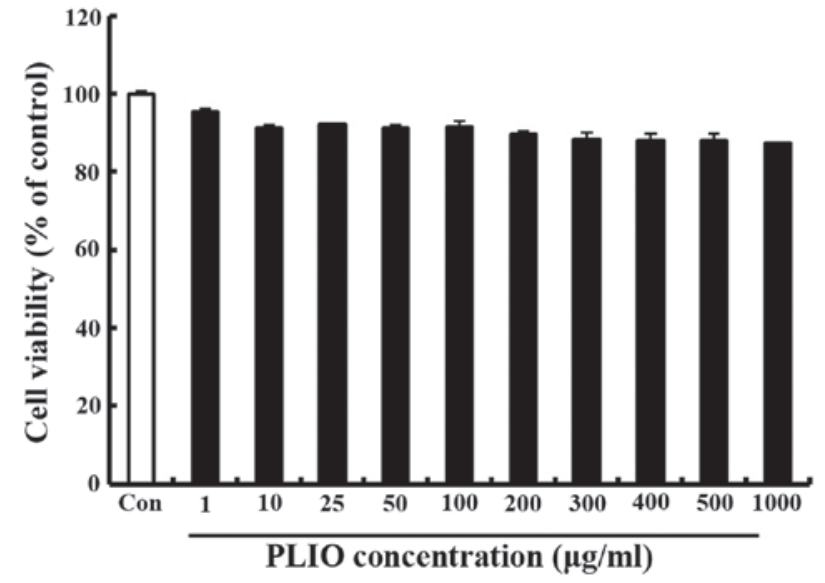

Figure 1. Effect of PLIO on viability of B16-F10 cells. Cells were treated with the indicated concentrations of PLIO for $24 \mathrm{~h}$. Cell viability was measured by the MTT assay. The results are presented as the mean \pm standard error of the mean. PLIO, polysaccharides derived from I. obliquus.

nucleic acid binding dye were used. Following staining of the cell population with the double staining method, apoptotic cells exhibit green fluorescence, dead cells exhibit red and green fluorescence, and live cells exhbit little or no fluorescence (22). Apoptotic cells were detected by flow cytometry. Low concentrations of PLIO $(25,50$, or $100 \mu \mathrm{g} / \mathrm{ml})$ did not increase apoptosis (Fig. 2A and B), suggesting that PLIO, at $\leq 100 \mu \mathrm{g} / \mathrm{ml}$, did not induce cell death or apoptosis in B16-F10 cells. This concentration range was then used in all subsequent experiments.

PLIO did not affect migration of B16-F10 cells, however, invasion of the melanoma cells was inhibited. To investigate whether PLIO had in vitro anti-metastatic activity, the present study evaluated B16-F10 cell migration and invasion in the presence of PLIO using gelatin- or Matrigel-coated Transwell assays with polycarbonate filters (pore size, $8-\mu \mathrm{m}$ ). It was observed that B16-F10 cells migrated from the upper chamber to the lower chamber in the untreated control, suggesting that the cells are able to migrate through a gelatin-coated Transwell insert. PLIO at concentrations of 50 and $100 \mu \mathrm{g} / \mathrm{ml}$ did not inhibit B16-F10 cell migration, which was 97 and $92 \%$ of the control level, respectively (Fig. 3). In the results of the invasion assay, untreated B16-F10 cells moved from the upper chamber to the lower chamber, indicating that the melanoma cells can invade through the Transwell insert pre-coated with Matrigel (Fig. 4). However, the presence of PLIO had an inhibitory effect on the invasion of B16-F10 cells in a concentration-dependent manner. As presented in Fig. 4B, $100 \mu \mathrm{g} / \mathrm{ml}$ of PLIO significantly inhibited invasion of B16-F10 melanoma cell to $35 \%$ $(\mathrm{P}<0.05)$. Thus, $\mathrm{PLIO}$ could inhibit invasion of melanoma cells.

PLIO regulated the expression of MMP-2, MMP-7 and MMP-9 in melanoma cells. ECM degradation, which is key in cellular invasion, involves matrix-degrading proteinases, including MMPs. To determine whether PLIO suppressed MMP protein expression levels, western blotting was used. PLIO treatment decreased the expression of MMP-2 and MMP-9 in B16-F10 cells. Particularly, PLIO was observed to reduce the expression levels of MMP-7 (Fig. 5). These results suggest that PLIO regulated the expression level of MMPs. 
A
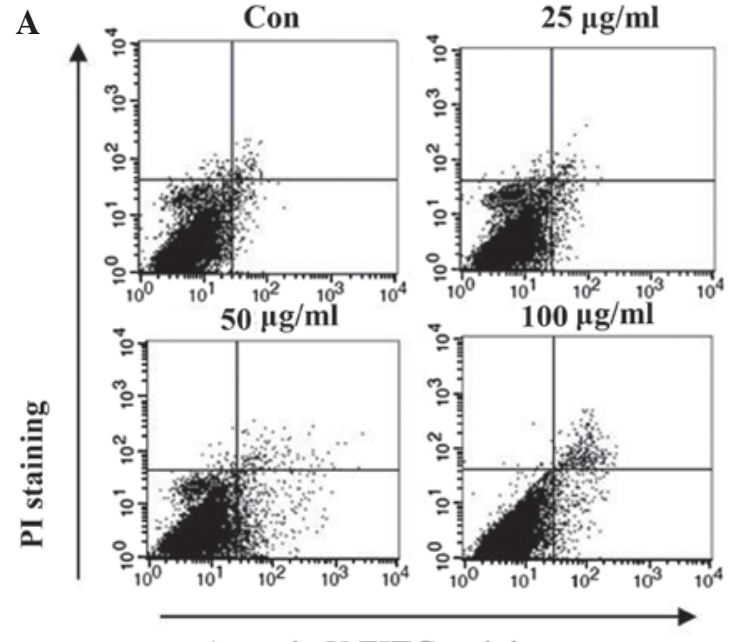

Annexin V-FITC staining
B

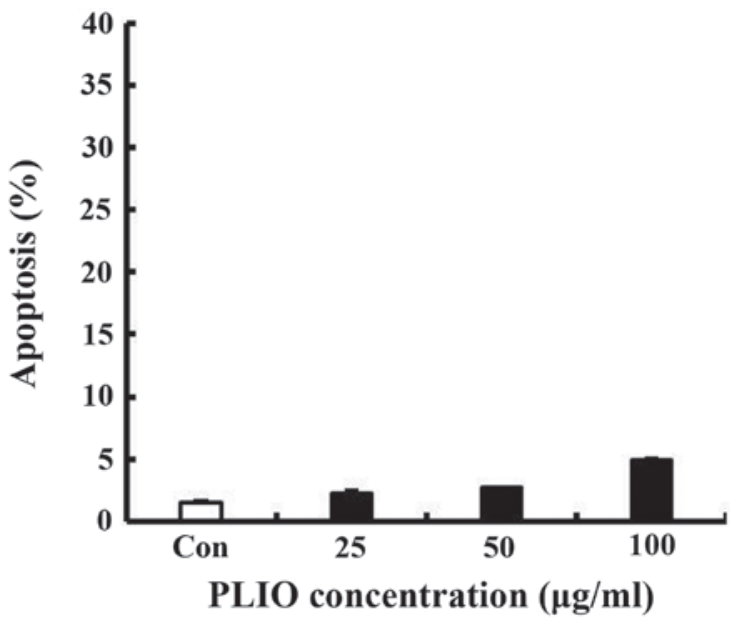

Figure 2. Effects of PLIO on apoptosis of B16-F10 cells. Cells were treated with the indicated concentrations of PLIO for 24 h. (A) Percentage of apoptotic cells after the treatment of PLIO in B16-F10 cells were measured by the Annexin V/PI flow cytometric analysis. (B) Apoptotic index (\%) was calculated as the sum of early and late apoptotic cells divided by the total number of events. Con, control; PI, propidium iodide; FITC, fluorescein isothiocyanate; PLIO, polysaccharides derived from I. obliquus.

A
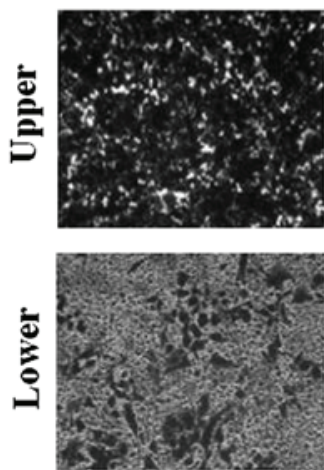

$50 \mu \mathrm{g} / \mathrm{ml}$
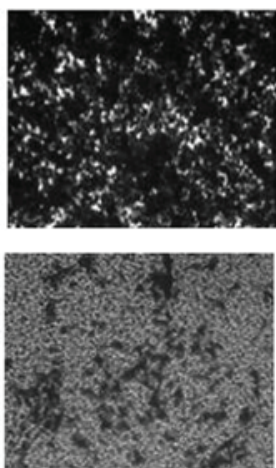

$100 \mu \mathrm{g} / \mathrm{ml}$
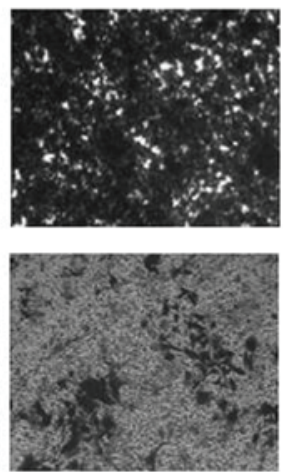

B

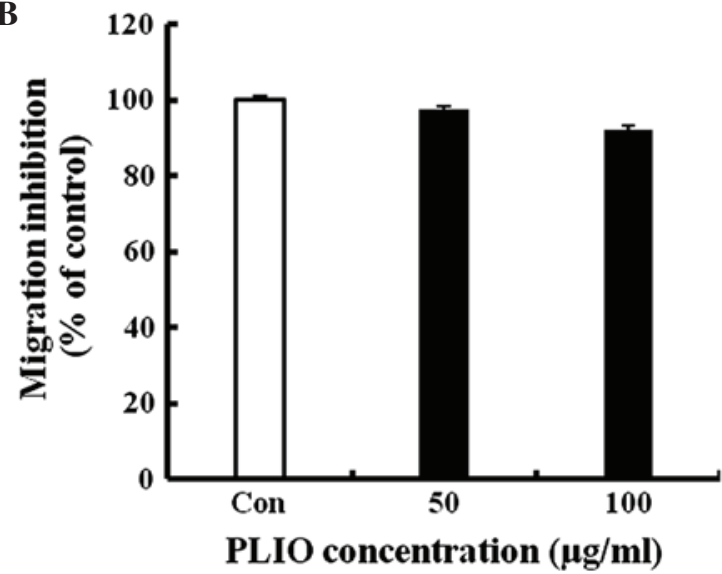

Figure 3. Effects of PLIO on the migration of B16-F10 cells. Cells were treated with the indicated concentrations of PLIO for 24 h. (A) Cell migration assays were performed using gelatin-coated Transwell chambers. (B) Cells that migrated through the gelatin were stained with $2 \%$ crystal violet, images were captured and the cells were counted under a light microscope (magnification, x40). PLIO, polysaccharides derived from I. obliquus; Con, control.

A
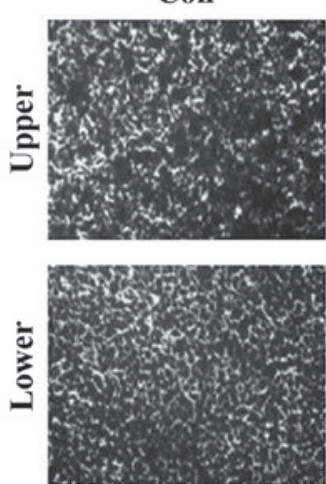

$50 \mu \mathrm{g} / \mathrm{ml}$
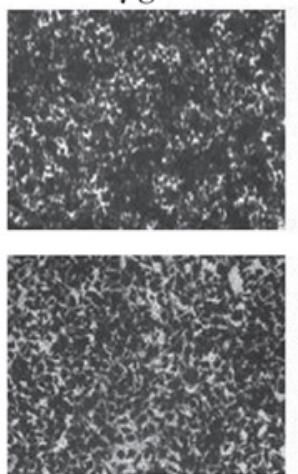

$100 \mu \mathrm{g} / \mathrm{ml}$
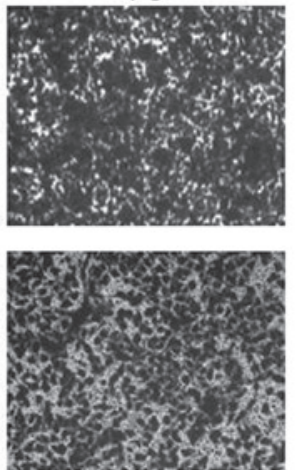

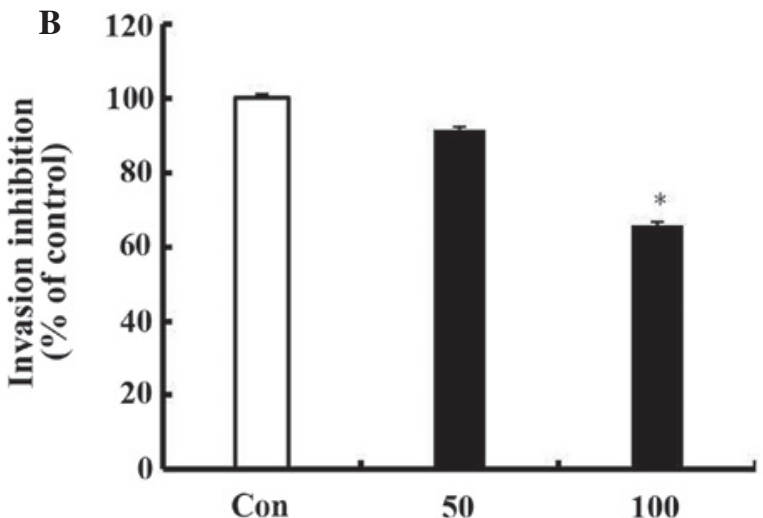

PLIO concentration $(\mu \mathrm{g} / \mathrm{ml})$

Figure 4. Effect of PLIO on the invasiveness of B16-F10 cells. Cells were treated with the indicated concentrations of PLIO for 24 h. (A) Cell invasion assays were performed using Matrigel-coated Transwell chambers. (B) Cells that invaded through the Matrigel were stained with $2 \%$ crystal violet, images were captuted and cells were counted under a light microscope (magnification, $\mathrm{x} 40$ ). ${ }^{*} \mathrm{P}<0.05$ vs. the control group. PLIO, polysaccharides derived from I. obliquus; Con, control. 


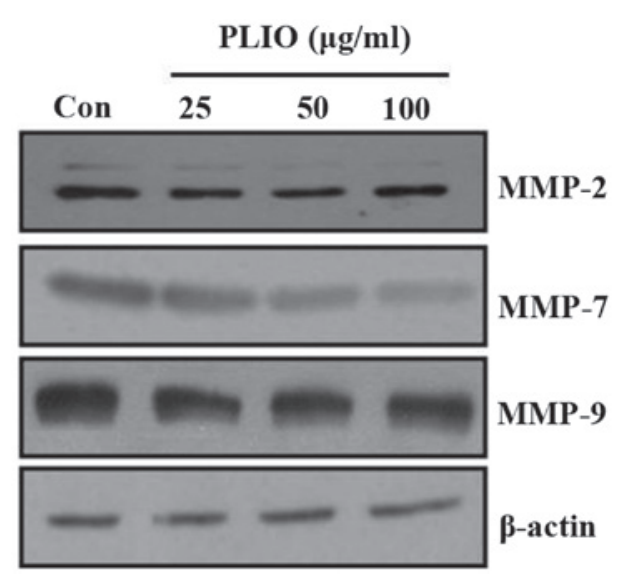

Figure 5. Effect of PLIO on the expression of MMPs in B16-F10 cells. Cells were treated with the indicated concentrations of PLIO in serum-free medium for $24 \mathrm{~h}$. Western blot analysis was used to determine the expression levels of MMP-2, MMP-7, and MMP-9. PLIO, polysaccharides derived from I. obliquus; Con, control; MMP, matrix metalloproteinase.

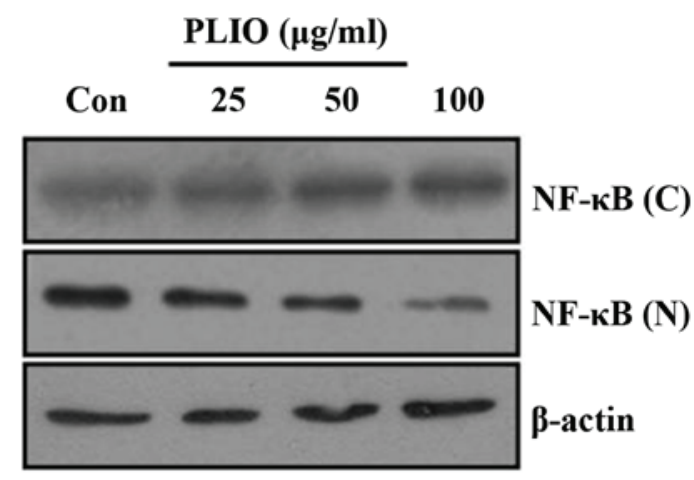

Figure 6. Effect of PLIO on NF-кB translocation in B16-F10 cells. Cells were treated with the indicated concentrations of PLIO for $24 \mathrm{~h}$. The nuclear $(\mathrm{N})$ and cytosolic (C) fractions from the PLIO-treated cells were isolated and analyzed for the expression of NF- $\mathrm{kB}$ using western blot analysis. PLIO, polysaccharides derived from I. obliquus; Con, control; NF-кB, nuclear factor- $\mathrm{\kappa} \mathrm{B}$.

PLIO inhibited $N F-\kappa B$ nuclear translocation in melanoma cells. To investigate whether PLIO inhibits the activation of the NF- $\mathrm{KB}$ signaling pathway in melanoma cells, the current investigated the effects of PLIO on translocation of the NF- $\mathrm{kB}$ protein from the cytoplasm to the nucleus. Western blotting was used to determine the levels of NF- $\mathrm{BB}$ translocation. Cytosolic protein levels of NF- $\mathrm{KB}$ in B16-F10 cells were higher in PLIO-treated cells than those in untreated cells (Fig. 6). By contrast, PLIO treatment markedly decreased nuclear protein levels of NF-kB compared with the levels in the untreated control. These results suggest that PLIO inhibited the activation of NF-kB in melanoma cells.

PLIO inhibited phosphorylation of JNK and AKT in melanoma cells. A previous study demonstrated that the activation of the PI3K/AKT and MAPK signaling pathways promotes cancer cell invasion and migration (23). It was demonstrated that PI3K/AKT and MAPK signaling pathways in different tumor cell types may be partially responsible for induction of MMP expression $(14,16,24)$. To investigate whether PLIO regulates PI3K/AKT and MAPK signaling pathways in melanoma cells,

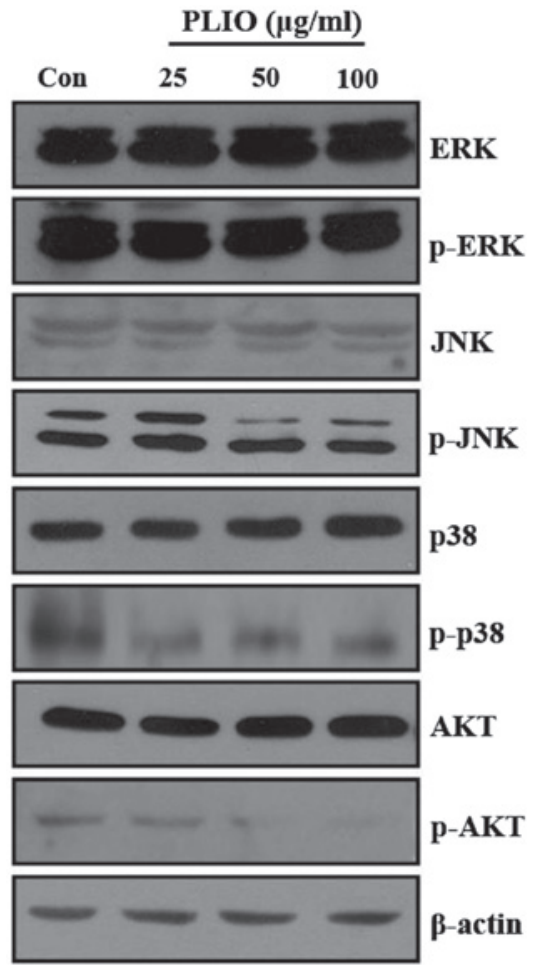

Figure 7. Effect of PLIO on AKT and MAPK pathways in B16-F10 cells. Cells were treated with the indicated concentrations of PLIO for $24 \mathrm{~h}$. The expression and phosphorylation levels of ERK, JNK, p38 MAPK, and AKT were assessed by western blot analysis. PLIO, polysaccharides derived from I. obliquus; Con, control; p, phosphorylated; ERK, extracellular signal-regulated kinase; JNK, c-Jun N-terminal kinases.

the levels of p-ERK, p-p38 MAPK, p-JNK, and p-AKT protein in B16-F10 cells were evaluated by western blot analysis following PLIO treatment. The western blotting demonstrated that the protein expression levels of PI3K/AKT and MAPK was not affected by PLIO treatment, however, the phosphorylation levels of JNK and AKT were inhibited by the addition of PLIO at 50 and $100 \mu \mathrm{g} / \mathrm{ml}$ (Fig. 7). This suggests PLIO inhibited the phosphorylation of JNK and AKT in B16-F10 cells.

\section{Discussion}

Research has recently focused on the anti-tumor properties of natural components for their potential chemotherapeutic applications. Polysaccharides are often associated with notable pharmacological activities. For example, polysaccharides extracted from mushrooms, including Agaricus blazei, Phellinus linteus, Hericium erinaceus, and I. obliquus exhibit important pharmacological properties. Tumor metastasis is a multi-step process, with complex regulation, which includes angiogenesis, cell attachment, adhesion, migration, invasion, and cell proliferation $(25,26)$. Developing therapeutic agents that inhibit metastasis is considered key, however, effective anti-metastatic agents require further research. The extracellular matrix and basement membrane are stable structures that provide organizational structure. MMPs, which are important for the degradation of extracellular matrix and basement membrane, have been extensively studied and their expression demonstrated to be markedly increased in a variety of types of cancer. In addition, MMPs promote cancer growth 
by activating cancer tissue growth factors and inhibiting the apoptosis of cancer cells. MMPs are key in physiological and pathological matrix turnover. Numerous reports have indicated that the expression levels of MMP-1, -2, -7, -9, and -10 are notably increased during cancer cell invasion, and may serve as independent prognostic factors for unfavorable prognosis $(14,24)$. MMP-7 expression in primary melanomas and in metastatic melanoma has been associated with melanoma progression and cell invasion (27). The present study investigated whether PLIO suppressed melanoma cell migration and invasion in vitro. The results demonstrated that PLIO suppressed the invasive ability of B16-F10 melanoma cells and suppressed the expression of MMPs in B16-F10 cells. Previous reports have demonstrated that the activation of activator protein 1 and $\mathrm{NF}-\kappa \mathrm{B}$ via multiple signaling pathways may induce transcription of MMPs and enhance the invasion of tumor cells $(28,29)$. In the present study, PLIO suppressed the expression of MMPs and inhibited the translocation of $\mathrm{NF}-\kappa \mathrm{B}$ from the cytosol to the nucleus in melanoma cells. These results indicate that PLIO inhibits the metastasis of B16-F10 cells by suppressing the expression of MMPs via inhibiting the $\mathrm{NF}-\kappa \mathrm{B}$ signaling pathway. It was reported that $\mathrm{COX}-2$, one of the downstream targets of $\mathrm{NF}-\kappa \mathrm{B}$, is important in angiogenesis, invasion and migration. It has also been demonstrated to modulate the expression of MMPs (30). The way in which MMPs are regulated by upstream factors, including COX-2, has been investigated in previous studies $(31,32)$. Although multiple genetic alterations are required in cancer invasion and metastasis, COX-2 is involved in the progression of cancer and may be useful in the development of targeted therapies in cancer cells. The current study demonstrated that protein expression levels of COX-2 in B16-F10 cells treated with PLIO were lower than those in the untreated cells, although this difference was not indicated to be statistically significant (data not shown). PLIO may also regulate the invasion of B16-F10 melanoma cells via different mechanisms, including PI3K/AKT and MAPK signaling pathways. It is generally demonstrated that the PI3K/AKT and MAPK signaling pathways regulate metastasis in a variety of cancer cells.

In conclusion, inhibition of metastasis is a key issue in cancer research. PLIO may inhibit the invasion of highly invasive melanoma cells by inhibiting MMPs expression via downregulation of the NF- $\mathrm{NB}, \mathrm{AKT}$, and/or MAPK signaling pathways. Based on these findings, the exact underlying anti-metastatic mechanism of PLIO is remains unclear, however, it is concluded that PLIO exhibits potent anti-metastatic effects.

\section{Acknowledgements}

The present study was supported by a grant from the National Institute of Biological Resources, funded by the Ministry of Environment of the Republic of Korea (grant no. NIBR201528101).

\section{References}

1. Zheng W, Miao K, Liu Y, Zhao Y, Zhang M, Pan S and Dai Y: Chemical diversity of biologically active metabolites in the sclerotia of Inonotus obliquus and submerged culture strategies for up-regulating their production. Appl Microbiol Biotechnol 87: $1237-1254,2010$.
2. Ma L, Chen H, Dong P and Lu X: Anti-inflammatory and anticancer activities of extracts and compounds from the mushroom Inonotus obliquus. Food Chem 139: 503-508, 2013.

3. Mu H, Zhang A, Zhang W, Cui G, Wang S and Duan J: Antioxidative properties of crude polysaccharides from Inonotus obliquus. Int J Mol Sci 13: 9194-9206, 2012.

4. Fan L, Ding S, Ai L and Deng K: Antitumor and immunomodulatory activity of water-soluble polysaccharide from Inonotus obliquus. Carbohydr Polym 90: 870-874, 2012.

5. Shibnev VA, Mishin DV, Garaev TM, Finogenova NP, Botikov AG and Deryabin PG: Antiviral activity of Inonotus obliquus fungus extract towards infection caused by hepatitis $C$ virus in cell cultures. Bull Exp Biol Med 151: 612-614, 2011.

6. Xu HY, Sun JE, Lu ZM, Zhang XM, Dou WF and Xu ZH: Beneficial effects of the ethanol extract from the dry matter of a culture broth of Inonotus obliquus in submerged culture on the antioxidant defence system and regeneration of pancreatic beta-cells in experimental diabetes in mice. Nat Prod Res 24: 542-553, 2010.

7. Xu X, Hu Y and Quan L: Production of bioactive polysaccharides by Inonotus obliquus under submerged fermentation supplemented with lignocellulosic biomass and their antioxidant activity. Bioprocess Biosyst Eng 37: 2483-2492, 2014.

8. Kabbaj W, Brecheret S, Guimberteau J, Talou T, Oliver JM, Bensoussan M, Sobal M and Roussos S: Comparison of volatile compound production in fruit body and in mycelium of Pleurotus ostreatus identified by submerged and solid-state cultures. Appl Biochem Biotechnol 102-103: 463-469, 2002.

9. $\mathrm{Xu} \mathrm{X,} \mathrm{Wu} \mathrm{Y} \mathrm{and} \mathrm{Chen} \mathrm{H}$ : Comparative antioxidative characteristics of polysaccharide-enriched extracts from natural sclerotia and cultured mycelia in submerged fermentation of Inonotus obliquus. Food Chem 127: 74-79, 2011.

10. Monks NR, Biswas DK and Pardee AB: Blocking anti-apoptosis as a strategy for cancer chemotherapy: NF-kappaB as a target. J Cell Biochem 92: 646-650, 2004.

11. Walsh V and Goodman J: Cancer chemotherapy, biodiversity, public and private property: The case of the anti-cancer drug taxol. Soc Sci Med 49: 1215-1225, 1999.

12. Han JY, Kim HS, Lee SH, Park WS, Lee JY and Yoo NJ: Immunohistochemical expression of integrins and extracellular matrix proteins in non-small cell lung cancer: Correlation with lymph node metastasis. Lung Cancer 41: 65-70, 2003.

13. Gacko M: Matrix metalloproteases (MMPS). Postepy Hig Med Dosw 51: 577-589, 1997 (In Polish).

14. Vivanco I and Sawyers CL: The phosphatidylinositol 3-kinase AKT pathway in human cancer. Nat Rev Cancer 2: 489-501, 2002.

15. Kim D, Kim S, Koh H, Yoon SO, Chung AS, Cho KS and Chung J: Akt/PKB promotes cancer cell invasion via increased motility and metalloproteinase production. FASEB J 15: 1953-1962, 2001.

16. Naugler WE and Karin M: NF-kappaB and cancer-identifying targets and mechanisms. Curr Opin Genet Dev 18: 19-26, 2008.

17. Lee KR, Lee JS, Song JE, Ha SJ and Hong EK: Inonotus obliquus-derived polysaccharide inhibits the migration and invasion of human non-small cell lung carcinoma cells via suppression of MMP-2 and MMP-9. Int J Oncol 45: 2533-2540, 2014.

18. Lee KR, Lee JS, Kim YR, Song IG and Hong EK: Polysaccharide from Inonotus obliquus inhibits migration and invasion in B16-F10 cells by suppressing MMP-2 and MMP-9 via downregulation of NF- $\kappa B$ signaling pathway. Oncol Rep 31: 2447-2453, 2014.

19. Kwon JS, Lee JS, Shin WC, Lee KE and Hong EK: Optimization of culture conditions and medium components for the production of mycelial biomass and exo-polysaccharides with Cordyceps militaris in liquid culture. Biotechnol Bioprocess Eng 14: 756-762, 2009.

20. Plumb JA: Cell sensitivity assay: The MTT assay. Methods Mol Med 28: 25-30, 1999.

21. M D and Brooks SA: In vitro invasion assay using matrigel ${ }^{\circledR}$. Methods Mol Med 58: 61-70, 2001.

22. Niu G and Chen X: Apoptosis imaging: Beyond annexin V. J Nucl Med 51: 1659-1662, 2010.

23. Kang MH, Oh SC, Lee HJ, Kang HN, Kim JL, Kim JS and Yoo YA: Metastatic function of BMP-2 in gastric cancer cells: The role of PI3K/AKT, MAPK, the NF- $\mathrm{BB}$ pathway, and MMP-9 expression. Exp Cell Res 317: 1746-1762, 2011.

24. Shiomi T and Okada Y: MT1-MMP and MMP-7 in invasion and metastasis of human cancers. Cancer Metastasis Rev 22: $145-152,2003$. 
25. Bartolome RA, Barderas R, Torres S, Fernandez-Aceñero MJ, Mendes M, García-Foncillas J, Lopez-Lucendo M and Casal JI Cadherin-17 interacts with $\alpha 2 \beta 1$ integrin to regulate cell proliferation and adhesion in colorectal cancer cells causing liver metastasis. Oncogene 33: 1658-1669, 2014.

26. Zanina N, Mora L, Othmane A, Bénard M, Duncan A, Jouenne T, Vaudry D and Souiri M: Differences in Caco-2 cell attachment, migration on collagen and fibronectin coated polyelectrolyte surfaces. Biotechnol Bioprocess Eng 18: 144-154, 2013.

27. Kawasaki K, Kawakami T, Watabe H, Itoh F, Mizoquchi M and Soma Y: Expression of matrilysin (matrix metalloproteinase-7) in primary cutaneous and metastatic melanoma. Br J Dermatol 156: 613-619, 2007.

28. Bergman MR, Cheng S, Honbo N, Piacentini L, Karliner JS and Lovett DH: A functional activating protein 1 (AP-1) site regulates matrix metalloproteinase 2 (MMP-2) transcription by cardiac cells through interactions with JunB-Fra1 and JunB-FosB heterodimers. Biochem J 369: 485-496, 2003.
29. Ding D, Xi P, Zhou J, Wang M and Cong YS: Human telomerase reverse transcriptase regulates MMP expression independently of telomerase activity via NF- $\mathrm{BB}$-dependent transcription. FASEB J 27: 4375-4383, 2013.

30. Zhang J, Luo J, Ni J, Tang L, Zhang HP, Zhang L, Xu JF and Zheng D: MMP-7 is upregulated by COX-2 and promotes proliferation and invasion of lung adenocarcinoma cells. Eur J Histochem 58: 2262, 2014.

31. Scoditti E, Nestola A, Massaro M, Calabriso N, Storelli C, De Caterina R and Carluccio MA: Hydroxytyrosol suppresses MMP-9 and COX-2 activity and expression in activated human monocytes via PKC $\alpha$ and PKC $\beta 1$ inhibition. Atherosclerosis 232: $17-24,2014$

32. Xue J, Hua YN, Xie ML and Gu ZL: Aspirin inhibits MMP-9 mRNA expression and release via the PPARalpha/gamma and COX-2/mPGES-1-mediated pathways in macrophages derived from THP-1 cells. Biomed Pharmacother 64: 118-123, 2010 . 